\title{
Estado, Economia e Democracia no Brasil Atual: Nota Crítica
}

\section{Guilherme Ribeiro}

\section{Q OpenEdition \\ 1 Journals}

\section{Edição electrónica}

URL: http://journals.openedition.org/espacoeconomia/1735

DOI: 10.4000/espacoeconomia.1735

ISSN: 2317-7837

\section{Editora}

Núcleo de Pesquisa Espaço \& Economia

\section{Refêrencia eletrónica}

Guilherme Ribeiro, "Estado, Economia e Democracia no Brasil Atual: Nota Crítica », Espaço e Economia [Online], 6 | 2015, posto online no dia 10 agosto 2015, consultado o 22 setembro 2020. URL : http:// journals.openedition.org/espacoeconomia/1735; DOI : https://doi.org/10.4000/espacoeconomia. 1735

Este documento foi criado de forma automática no dia 22 setembro 2020.

(c) NUPEE 


\title{
Estado, Economia e Democracia no Brasil Atual: Nota Crítica
}

\author{
Guilherme Ribeiro
}

1 Quando a ânsia por dinheiro e poder assumem o centro da vida social em tempos pósmodernos, que podemos esperar senão egoísmo, narcisismo e superficialidade? Esse parece ser o caso do Brasil atual, expressão perfeita da dupla crise da economia e da governança. Inebriado por uma alta dose de ingenuidade e de amnésia histórica, o Estado depositou todas as suas esperanças no desenvolvimentismo, capitaneado, desta vez, pela indústria petrolífera. No ano de 2006, a Petrobras anunciou o maior investimento de sua história, o Comperj, como se representasse o ingresso definitivo do país em uma era de prosperidade e bonança. Em nossos dias, a empresa vive aquela que é, provavelmente, sua crise de maiores proporções, caracterizada pela má gestão e pela corrupção de seus principais dirigentes vinculados a algumas das maiores empreiteiras brasileiras - Odebrecht, por exemplo. Em agosto de 2012, a presidente Dilma Rousseff convocou reunião com os maiores empresários nacionais lançando programa bilionário de concessão de rodovias e ferrovias. Ao fim do espetáculo, o patriota Eike Batista, incensado pela mídia brasileira e internacional como um dos homens mais ricos do mundo e ícone do Brasil do século XXI, definiu tal iniciativa como um "kit-felicidade" (ver RIBEIRO, 2012). Como se sabe, atualmente o Sr. Batista responde a processo judicial por operações ilícitas na bolsa de valores e, como se não bastasse, todos os seus negócios foram à falência. Tão ou mais ávidos por dinheiro fácil e rápido, seus próprios acionistas lhe processaram: eis a face mais dantesca do capitalismo!

2 Na esfera política, se PSDB e PT jogaram papel de inquestionável relevo nos mandatos de Fernando Henrique Cardoso (1995-2002) e Luis Inácio Lula da Silva (2003-2010), o primeiro atuando decisivamente na conquista da estabilidade monetária e o segundo na redução das desigualdades sociais, nos últimos anos ambos foram protagonistas do que há de pior na política nacional, fazendo do Congresso verdadeiro balcão de negócios e de negociatas em nome da "governabilidade". Incapazes de promover as reformas política e tributária desejadas por todas as camadas da sociedade, ao apelarem respectivamente para o neoliberalismo e para o aparelhamento do Estado, PSDB e PT 
contribuíram, cada qual à sua maneira, para o descrédito do Legislativo e, para alguns, da democracia.

Do ponto de vista teórico, talvez esse seja um dos nossos maiores dilemas: a indistinção entre o público e o privado, cujo resultado mais pernicioso é, exatamente, a fragilidade das instituições. A esquizofrenia é conhecida por todos: basta alguém assumir um posto de comando no setor público para, imediatamente, agir como se fosse dono, proprietário, senhor e, claro, ser assediado por um grupo que só sobrevive às custas de "trocas de favores". Qualquer semelhança com o PMDB não é mera coincidência, digase. Ele não é uma exceção; muito pelo contrário, é a institucionalização de uma prática que, infelizmente, atravessa todo o corpo social nacional.

Esboçamos a situação acima notadamente para responsabilizar a sociedade pela cristalização dessa estrutura, pois os indivíduos que confundem interesses públicos e privados nas mais diferentes escalas da vida cotidiana são os mesmos que assaltam as ruas poucos meses depois das eleições presidenciais exigindo a renúncia e, mesmo, o impeachment, de Dilma Rousseff. Obviamente, trata-se de profunda incompreensão acerca do papel das instituições republicanas e da democracia na constituição da sociedade moderna.

5 Nesse contexto, não surpreende a emergência de, pelo menos, três tipos de radicalismo: o de direita, que grita toda vez que seus privilégios individuais são questionados e, no limite, apela para o militarismo como solução de todos os males ${ }^{1}$; o de esquerda, que só enxerga a face negativa da economia de mercado, é inábil para operar uma única crítica construtiva ao Partido dos Trabalhadores ${ }^{2} \mathrm{e}$, não raro, continua a idealizar o socialismo como alternativa; e o do poder paralelo, que, representado majoritariamente pelo tráfico de drogas e pela cadeia de violência dele decorrente, há tempos desistiu de esperar algo do Estado e de suas instituições.

Definitivamente, o Brasil não caminha bem, e não estamos nos referindo ao preocupante aumento da inflação nos últimos três anos, à espetacularização da política operada pelo atual Congresso Nacional e pelo Executivo ou ao visível empobrecimento da capacidade analítica dos principais jornais do país ${ }^{3}$, mas, sim, a uma questão estrutural: o pacto acordado entre sociedade e Estado. Nossa memória insistentemente lacunar não pode negligenciar as amplas e memoráveis manifestações populares urbanas ocorridas em junho de 2013. Embora o aumento do preço das passagens de ônibus possa ter sido o estopim do movimento, de fato a péssima infra-estrutura urbana, o descaso em relação a serviços públicos essenciais como saúde e educação, o profundo descontentamento diante da atuação dos partidos políticos e a discordância face aos altos custos da Copa do Mundo patrocinada por fundos públicos integraram o cerne da questão (ver RIBEIRO, 2013; BOTELHO, 2013; OLIVEIRA, 2013) que, dentre outras leituras, pode ser traduzida da seguinte maneira: existe notória insatisfação da sociedade brasileira no que se refere às ações estatais. Tanto na ocasião quanto em nossos dias, o uso intenso da força policial quando a população se levanta contra determinadas atitudes governamentais é exemplo contundente de que os poderes constituídos estão de costas para a sociedade.

7 Um dos efeitos mais deletérios desse cenário é a perda de sentido daquilo que é público e, simultaneamente, a capacidade dos indivíduos de se reconhecerem como integrantes de uma sociedade. $\mathrm{O}$ caótico transporte urbano, o alto índice de violência nas grandes cidades, a ausência de diálogo maduro entre Legislativo e Executivo e a corrupção na Petrobras não estão, grosso modo, diretamente associados ao incipiente 
reconhecimento da centralidade da coisa pública pela sociedade brasileira? Aqui, desafortunadamente, a história não nos é favorável: as consequências do escravismo se fazem sentir até hoje, o mandonismo local permanece em várias áreas do interior do país e, de Vargas às ditaduras militares, a maior parte do século passado esteve nas mãos de governos autoritários.

Portanto, nossos males são, de fato, estruturais? Não se pode fazer nada contra eles? Claro está que avanços de relevo - basta lembrar os anos oitenta - foram perpetrados em uma série de aspectos: otimização e transparência dos gastos públicos; ampliação da educação às camadas desfavorecidas; aumento do poder de compra da população; incremento dos gastos em ciência e tecnologia; diminuição do desemprego; direitos das minorias; combate ao racismo. Entretanto, é preciso ir além: limitada à participação no período eleitoral, esvazia-se o amplo sentido da democracia, que, como se sabe, deve incorporar o maior número de cidadãos ${ }^{4}$. Além disso, em plena era digital, partidos políticos (e os excessos do regime presidencialista) não podem monopolizar decisões que afetam toda a sociedade - como se esta, muitas vezes, não existisse! É preciso estabelecer metas econômicas e sociais de longo prazo, e não sujeitar-se a um casuísmo que corrói práticas verdadeiramente democráticas. Nessa direção, consideramos absoluto retrocesso recente lei que põe fim à reeleição, pois somente quatro anos de mandato pode contribuir ainda mais para a superficialidade e o não-planejamento nas áreas de saúde, educação e infra-estrutura urbana. Afinal, o tempo da elaboração, da consecução e dos resultados de políticas públicas estruturais não é e não deve ser o tempo dos interesses pontuais do mercado. Muito pelo contrário: é precisamente em momentos de crise econômica que a força das instituições e de tais políticas devem prevalecer, pois, como se sabe, o mercado "investe" basicamente naquilo que lhe trará dividendos rápidos $\mathrm{e}$ altos. Como são resistentes $\mathrm{o}$ economicismo $\mathrm{e} \quad \mathrm{o}$ desenvolvimentismo - mesmo diante da brutal crise urbana-industrial em que vivemos e da própria decadência do setor secundário na criação de riquezas em comparação às áreas de informática e alta tecnologia (vide AREND, 2015 [2014]).

9 Por tudo isso, urge ressucitar a política - um dos maiores desafios éticos do nosso século.

10 O sexto número da Espaço e Economia. Revista Brasileira de Geografia Econômica prossegue seu esforço de divulgar investigações críticas ao redor do capitalismo e da geografia humana de modo geral.

11 Professor do Instituto Federal Fluminense - Campos dos Goytacazes e doutorando no Programa de Políticas Públicas e Formação Humana da UERJ, Roberto Moraes realiza importante interpretação da influência que o petróleo produz na economia e no desenvolvimento regional, tanto no norte do Rio de Janeiro (devido à concentração das atividades de extração e distribuição do produto) quanto em todo o território fluminense. A partir de um breve resgate da história da internacionalização da economia da região norte pela comercialização dos produtos derivados da cana de açúcar nos séculos XIX e XX, o autor passa a enfatizar o novo processo de internacionalização por efeito da denominada "economia do petróleo". Opera, para melhor compreensão do leitor, uma análise sobre a trajetória da formação dos capitais corporativos na área do petróleo em todo o mundo, bem como apresenta interessante evolução da crise e dos preços do petróleo no mercado mundial. Nesse mesmo sentido, apresenta também histórico do desenvolvimento da industria do petróleo no Brasil, identificando marcos temporais e estruturais pouco conhecidos no país. 
12 Na segunda parte do trabalho, o autor introduz os elementos estruturantes na economia e no território do estado do Rio de Janeiro, em especial na parte norte fluminense, do que nomeia "economia do petróleo" e "economia dos royalties". Tratase, por um lado, de uma abordagem do fenômeno distinguindo os efeitos da cadeia produtiva do petróleo, instituinte de renovação na estrutura produtiva no território e desenvolvimento de um importante parque industrial, tanto de apoio às atividades offshore quanto de indústrias de equipamentos pesados como navios e plataformas. Por outro lado, com muita clareza e objetividade, Moraes analisa os efeitos da economia dos royalties, referindo-se aos recursos que são pagos aos governos do estado e dos municípios e que implicam em aumento significativo da arrecadação municipal e estadual que, embora contribua para a economia local, não representa melhorias estruturais na economia do estado.

Em Os efeitos da reestruturação econômica metropolitana na Baixada Fluminense: apontamentos sobre o 'novo' mercado imobiliário da região, André Santos da Rocha também professor permanente do PPGGEO/UFRRJ e coordenador do Laboratório de Geografia Econômica e Política e Práticas Educativas (LAGEPPE) - expõe as mudanças do perfil imobiliário da Baixada Fluminense, situada na Região Metropolitana do Rio de Janeiro. Historicamente marcada pelo estigma da pobreza e da segregação, a Baixada Fluminense vem assistindo a uma profunda valorização do solo urbano, algo que reverbera não somente no encarecimento das moradias e nas mudanças de feição do público que as consome, mas também na edificação recente de shoppings, apart-hotéis, condomínios logísticos e outras formas imobiliárias. Uma nova geografia econômica da habitação emerge sem, necessariamente, romper com as mazelas existentes no lugar.

Escrito pelo bolsista de iniciação científica do CNPq e estudante de geografia Gabriel Teixeira (UERJ), Reestruturação imobiliária no Rio de Janeiro (RJ): agentes e transformações urbanas na área central da cidade apresenta um processo de segregação anunciada em curso na cidade do Rio de Janeiro. Analisa as mudanças no uso do solo urbano em duas áreas degradadas no centro da cidade cuja recuperação tem consumido recursos públicos, mas denuncia que as novas formas de ocupação são dirigidas por empreendimentos imobiliários de capitais estrangeiros. $O$ autor investiga a origem dos capitais que estão dominando a renovação urbana por meio de edifícios corporativos, assim como a inexistência de projetos habitacionais ou de equipamentos urbanos que sejam de interesse social. Complementando sua argumentação, Teixeira destaca a falácia da associação entre essa renovação urbana e a realização dos megaeventos ocorridos na cidade. De fato, o que está em curso é uma apropriação de parte da cidade, por muito tempo abandonada, e que funcionou como "reserva de valor imobiliário". Atualmente, ela tem sido resgatada pelo capital corporativo, que localiza na produção do urbano nova fonte de acumulação.

15 Assinado por Maurilio Lima Botelho - professor permanente do recém-criado Programa de Pós-Graduação em Geografia da Universidade Federal Rural do Rio de Janeiro (PPGGEO/UFRRJ) -, Dinheiro e crédito em David Harvey: comentários críticos prossegue diálogo do autor com um dos principais geógrafos marxistas da atualidade. Com destaque para a obra clássica do britânico Os limites do capital (1982), Botelho promove rica e crítica discussão teórica em torno das ligações entre dinheiro e crédito, enfatizando os aspectos contraditórios pressupostos na relação original entre valor de uso e valor de troca, que se reproduz em diversos níveis até se transformar na radical oposição entre mercadoria e dinheiro. Esta relação cria as condições para as crises 
econômicas, em especial as irrupções financeiras. $\mathrm{O}$ artigo avalia alguns dos aspectos espaciais desta relação, mas, principalmente, explora os desdobramentos que culminaram com a quebra do padrão metálico das moedas. 0 acompanhamento da obra de Harvey para a compreensão desses aspectos não deixa de apontar algumas de suas recentes hesitações a respeito. Nesse sentido, Botelho busca nos fundamentos e nas influências teóricas algumas das possíveis explicações para o caminho trilhado por Harvey.

Por fim, pensando na internacionalização de nosso periódico e visando ampliar tanto o público francês quanto os francófonos ao redor do mundo, apresentamos no idioma de Jacques Prévert o artigo L'image de l'Algérie selon Bory de Saint-Vincent (1778-1846) et la construction d'un discours géographique colonial. Redigido por Laura Péaud - doutora em geografia pela Université Lumière Lyon 2 -, o texto revela os papéis do saber geográfico pré-universitário à época da expansão imperial francesa. Crítico das formas assumidas pela colonização argelina, Bory, segundo Peaud, estaria no limite entre a ciência e a política, ora pendendo para uma, ora para outra. De qualquer forma, é impossível desvencilhar a produção de conhecimento em geografia do contexto colonial de então, e a reflexão de Bory é um belo exemplo disto.

Na seção Trilhas de Pesquisa, Erich Moura -mestrando do Programa de Pós-Graduação em Geografia da UERJ-FFP - expõe sua pesquisa em andamento sobre os conflitos gerados pela implantação de um resort no litoral do município de Maricá-Rio de Janeiro em uma área de preservação ambiental (APA-Maricá). A área é formada por uma extensa restinga com forte incidência de fauna e flora características do ambiente de dunas e, por esta razão, tornou-se extremamente relevante como lócus de inúmeras pesquisas e monitoramento de espécies animais e vegetais em extinção. Não menos importante, constitui-se em espaço de moradia de pescadores artesanais residentes na Vila Zacarias. Em sua investigação, Moura critica a manipulação das leis ambientais por parte da administração pública municipal e do legislativo estadual, ambos promovendo alterações nos planos de ocupação de áreas de proteção para beneficiar os investidores luso-espanhóis do resort.

Mantendo nossa preocupação com o debate bibliográfico, a presente edição traz duas resenhas para o leitor : em Notas a respeito do "urbano": breve análise sobre a obra "Geografia urbana: ciência e ação política", o bolsista PIBID Ernane Fernandes Moura (UFRRJ) avalia o livro organizado por Floriano José Godinho de Oliveira (PPFH/UERJ e PPGG/UERJ), Désirée Guichard Freire (UERJ-FFP), Gilmar Mascarenhas (PPGEO/UERJ) e Leandro Dias de Oliveira (PPGGEO/UFRRJ). Resultado do XIII Simpósio Nacional de Geografia Urbana (SIMPURB) ocorrido na cidade do Rio de Janeiro em novembro de 2013, o livro é dividido em cinco partes: (i) Conferências de abertura e encerramento, proferidas respectivamente por Arlete Moysés Rodrigues e David Harvey; (ii) A produção do urbano: tendências contemporâneas, conflitos e resistências no espaço urbano; (iii) Economia urbana, desigualdades sociais e políticas públicas; (iv) Informação e comunicação nas práticas políticas e culturais na produção da cidade; (v) texto de Pedro Geiger, homenageado do evento. Trata-se, portanto, de um rico e diverso panorama acerca do que há de melhor na geografia urbana brasileira, campo disciplinar tão caro à geografia e que, como sublinhou Edward Soja, é impossível negligenciá-lo em nosso tempo (SOJA,2013:138 [2011]).

Em Meio ambiente, produção do espaço urbano e relações de poder: Um estudo sobre a implantação de parques em Ribeirão Preto - SP, Felipe de Souza Ramão - Mestre em 
Geografia pela Universidade do Estado do Rio de Janeiro e membro do Núcleo de Pesquisa Espaço e Economia - explora o livro Os Parques e a Produção do Espaço Urbano (2013) do professor Marcos Antônio Silvestre Gomes (UFTM) a fim de discutir o papel da natureza no espaço urbano atual. A partir do exemplo de Ribeirão Preto, cuja implementação de parques urbanos alimentou a especulação imobiliária, Ramão capta o quanto o livro revela a atual fetichização da natureza. Consolidada como "nova raridade" - expressão cunhada pelo filósofo francês Henri Lefebvre (1901-1991) e que atravessa todo o livro -, o parque urbano é um valor marginal da mercadoria "habitação" em tempos de cidades monocromáticas e insustentáveis. As análises de Gomes devem interessar a todos aqueles responsáveis pelo planejamento e por políticas públicas urbanas.

\section{BIBLIOGRAFIA}

AGUIAR, Thais Florencio de. A demofobia na democracia moderna. Dados - Revista de Ciências Sociais, Rio de Janeiro, vol. 54, n.4, pp.609-650 (2011).

AREND, Marcelo. A industrialização do Brasil ante a nova divisão internacional do trabalho. IPEA, Textos para discussão, jul, pp.7-54 (2015 [2014]).

BOTELHO, Maurilio Lima. O mundo como imagem e mobilização. Notas às "primeiras impressões" sobre as manifestações. Continentes. Revista de Geografia da Universidade Federal Rural do Rio de Janeiro, n.3, pp.121-132 (2013)

O’DONNELL, Guillermo. Delegative Democracy. Journal of Democracy, vol.5, n1, jan., pp.55-69 (1994).

OLIVEIRA, Leandro Dias de. Um novo despertar da luta política (ou Sobre os desafios da “democracia brasileira"). Continentes. Revista de Geografia da Universidade Federal Rural do Rio de Janeiro, n.3, pp.133-141 (2013).

RIBEIRO, Guilherme. A realização da política no Brasil urbano do século XXI: notas-testemunho. Continentes. Revista de Geografia da Universidade Federal Rural do Rio de Janeiro, n.3, pp.116-120 (2013). RIBEIRO, Guilherme. Fora de ordem. Jornal O Globo, Rio de Janeiro, p. 15 - 15, 27 de agosto (2012). SOJA, Edward. Para além de Postmetropolis. Revista UFMG, Belo Horizonte, v.20, n.1, pp136-167 (2013 [2011]).

\section{NOTAS}

1. Nas eleições de 2013, o militar da reserva Jair Bolsonaro foi o deputado federal mais votado pelo estado do Rio de Janeiro, totalizando quase meio milhão de votos (precisamente, 464.572). Na Câmara dos Deputados ele ocupa tal posto há vinte e quatro anos. Político profissional, ressalte-se. No mesmo pleito, seu filho Flávio Bolsonaro elegeu-se deputado estadual pelo Rio com 160.359 votos.

2. A decadência do Partido dos Trabalhadores tem evento simbólico com a expulsão de quadros como Heló́sa Helena, Babá e Luciana Genro, que cometeram a "heresia" de votar contra o próprio partido em eleições no Congresso Nacional. o posterior escândalo do "mensalão" tão somente corroboraria a direção equivocada tomada pelos dirigentes do partido. 
3. Pensamos sobretudo na decisão de encerrar o Caderno Mais!, suplemento cultural da Folha de São Paulo, no ano de 2010. Neste mesmo ano, o Jornal do Brasil editou seu último número impresso. A cobertura confusa e excessivamente conservadora do jornal o Globo quando das manifestações de junho de 2013 também serve de exemplo.

4. O receio, para não dizer preconceito, dos teóricos da democracia moderna em relação ao povo foi nomeado demofobia pela brasileira Thais Florencio de Aguiar, ao passo que o argentino Guillermo o'Donnell soube radiografar com lucidez a fragilidade institucional e representativa do que nomeou democracias delegativas - incluindo, claro, o Brasil (vide, respectivamente, AGUIAR, 2011; O'DONNELL, 1994).

\section{AUTOR}

\section{GUILHERME RIBEIRO}

Doutor em Geografia pela Universidade Federal Fluminense, com doutorado sandwich pela Universidade de Paris - Sorbonne (Paris IV). Pós-Doutor em Geografia pela Universidade Federal de Minas Gerais. Professor do Programa de Pós-Graduação em Geografia da Universidade Federal Rural do Rio de Janeiro e. E-mail: geofilos@msn.com 